\title{
Exploring the Role of Empathy in a Service-Learning Design Project
}

\author{
Nicholas D. Fila* and Justin L. Hess* \\ *equal authorship \\ Purdue University, West Lafayette, IN, United States \\ nfila@purdue.edu; jhess@purdue.edu
}

\begin{abstract}
The emergence of empathic design has inspired growing discourse on the role of empathy within design. While research on empathic design acknowledges the presence of empathy in design practice, little attention has been paid to its underlying mechanisms and how these mechanisms operate within the designer's mind throughout the design process. In this study, we used the service-learning data set to develop an emergent empathic design model. We collected and analyzed any instances in which designers evidenced empathy for the end users. We kept empathy loosely defined due to the exploratory intent of this study and the recognition that empathy by designers for users may show itself only subtly in designers' reflections on interactions with users.
\end{abstract}

Through thematic analysis of over 100 critical instances during the 8 service-learning videos, we discovered 4 higher level themes with 12 underlying patterns of empathy in the design process. These themes included (a) developing understanding - design behaviors oriented towards identifying and comprehending the perspectives of potential users, (b) identifying criteria and constraints - employing an empathic understanding of the user to set design goals and parameters, (c) generating design concepts - designers' empathic understanding of the user inspires new design concepts, and (d) evaluating design concepts - using empathy to determine the appropriateness of specific design concepts for the users. These themes, their underlying patterns, and 5 additional patterns associated with empathy but not considered empathic, were mapped to depict an empathic design model.

Keywords: Empathy, service-learning, engineering design, human-centered design, empathic design

\section{Significance}

This exploratory study continues the recent investigation on the role of empathy within design (Mattelmäki, Vaajakallio, \& Koskinen, 2014) and engineering (Strobel, Hess, Pan, \& Wachter Morris, 2013). Specifically, we explore how empathy contributes to designers' development of an understanding of users and how that understanding influences the designers' processes. The designers in our study consisted of a diverse group of nine STEM students at Purdue University, one student advisor, and one senior advisor. The users consisted of a group of differently-abled children who participated in a "camp for children with tracheostomies and those requiring respiratory assistance" (http://www.champcamp.org). The research questions are addressed through careful selection and thematic analysis (Braun \& Clarke, 2006) of critical events (Powell, Francisco, \& Maher, 2003), the instances where empathy by designers for users was apparent and salient. In-depth analysis of these critical events provides an avenue for articulating how empathy operated within a real-world design context, the specific role empathy played in 
the emergence of a design concept, and the emergence of a model of empathic design. This research was guided by the following research questions:

1. How do designers develop an empathic understanding of differently-abled users within a service-learning design course?

2. How do designers utilize user-centric knowledge in the development of a design concept?

\section{Theoretical Framework}

This project is informed by research on empathy within the fields of social psychology (Batson, Early, \& Salvarani, 1997; Davis, 1983, 1996; Hoffman, 2000), neuroscience (Batson, 2009; Iacoboni, 2009), and engineering (Strobel et al., 2013; Zoltowski, Oakes, \& Cardella, 2012). These resources provide an avenue for understanding what empathy is and, in turn, how empathy may operate within the world of engineering design.

In the context of human-centered design traditions, empathic skills such as understanding user needs within their own surrounding context are seen as essential to developing appropriate and innovative designs (Leonard \& Rayport, 1997; Mattelmäki et al., 2014; Postma, ZwartkruisPelgrim, Daemen, \& Du, 2012). This literature is using a relatively novel term, "empathic design," although discourse within this literature focusing on what empathy is and how it operates within empathic design is largely missing. The work by Zoltowski et al. (2012) carefully articulates what empathic design is (the most "comprehensive" form of human-centered design), but this work does not explicitly clarify how the "empathy" construct manifests itself within empathic design.

The empathic design literature seems to have an implicit assumption that we know exactly what empathy is. However, empathy is a nuanced construct. Batson (2009) suggested that eight different conceptualizations of empathy exist, ${ }^{1}$ and argued these conceptualizations stem from two distinct research questions, (a) "How can one know what another person is thinking and feeling?", and (b) "What leads one to respond with sensitivity and care to the suffering of another?" (p. 3). The former focuses on the cognitive understanding resulting from empathizing, whereas the latter focuses on behavioral responses as a result of understanding, feeling with, or feeling for another or others. In the realm of engineering design, empathy is often described as a tool to better understand direct users of engineering artifacts in the context in which the artifact would be used, and thus inspire or improve a design. In this engineering design space, these questions translate to: (a) "What does the designer understand about the user in context?" and (b) "How does that understanding inspire a design concept or alteration?"

In an education space, interaction with and empathy towards stakeholders may increase commitment and motivation to develop solutions that are ideal for the specific stakeholder.

\footnotetext{
${ }^{1}$ Batson's (2009) 8 distinctions include: (a) Knowing another person's internal state, including his or her thoughts and feelings, (b) Adopting the posture or matching the neural responses of an observed other, (c) Coming to feel as another person feels, (d) Intuiting or projecting oneself into another's situation, (e) Imagining how another is thinking and feeling, (f) Imagining how one would think and feel in the other's place, (g) Feeling distress at witnessing another person's suffering, and (h) Feeling for another person who is suffering.
} 
Zoltowski et al. (2012) suggested "immersive" experiences, where designers spend ample time to develop a positive relationship with a user, were one primary avenue to designing empathically. Here, empathic design involved understanding the users' needs less objectively, where the designer sees the user as a whole person rather than merely a source of design constraints.

Although Zoltowski et al. (2012) does not discuss this notion, immersive experiences are truly an avenue for designers to develop familiarity with users. Lacking such familiarity, the likelihood that designers truly and accurately empathize with users who are largely dissimilar from them is quite small. Hoffman (2000) defined three familiarity biases that dictate who one empathizes with: (a) in-group bias, (b) friendship bias, and (c) similarity bias (p. 207f). Hoffman also talks about here-and-now bias, suggesting we empathize more naturally with individuals spatially and temporally nearby. Such biases must be overcome if designers are to design empathically for users, especially users who are largely distinct from the designer.

Through review of the service learning videos in the Design Thinking Research Symposium (DTRS) 2014 data set, it appears the student designers are actively experiencing immersion with the users. While the designers may be largely dissimilar from the users and in distinct groups (e.g. age, physical ability), they appear to develop a friendship that is central to "empathic" design as articulated by Zoltowski et al. (2012), as evidenced by their warm verbal reflections of their interactions with the users. Therefore, to justify the feasibility of exploring the role empathy plays in design with the selected data set, we theorize that empathy is indeed present by the students (designers) for the users (campers). We recognize empathy is a nuanced construct and explore the ways in which it is present and what role its presence plays in the development of an engineering design concept. We do not limit ourselves to previous definitions of empathy within the stated literature, but rather use this literature as an ideological guide to our methods.

\section{Methods}

Our approach in this study was a seven-step procedure developed from a two-part amalgamation. The first component stems from a video analysis framework outlined by Powell et al. (2003) who specified a seven-step non-linear analytical model for examining data. The steps depicted by these authors included: (a) viewing the video data, (b) describing the data, (c) identifying critical events, (d) coding critical events, (e) constructing a storyline, and (f) composing a narrative. Steps d, e, and f involve thorough analysis of the identified "critical events", which can be described as "any significant moment" (p. 416). In our framework, a critical event represents any instance where empathy seems plausibly present or a user-centered consideration is verbalized. The second component of our method is a process of thematic analysis outlined by Braun and Clarke (2006). These authors proposed a method that proceeds in six steps: (a) becoming familiar with the data, (b) generating initial codes, (c) searching for themes, (d) reviewing themes, (e) defining and naming themes, and (f) producing the report. Integrating these two methods, our process was as follows:

1. Familiarizing ourselves with the video data by watching each video thoroughly at least twice and then reading interview transcripts

2. Describing the video data orally and in memos 
3. Identifying critical events within the videos and transcripts, where critical events were depicted as any instance in which empathy by the designer towards the user appears evident

4. Generating initial codes inductively through analysis of all selected critical events

5. Developing and organizing higher level themes based on inductively generated codes

6. Organizing themes in relation to each other visually and using this visualization to tell a story pertaining to our stated research questions

7. Composing a narrative to discuss the research findings

\subsection{Describing the Data}

Our focus was on a service-learning data set which provided a rich overview of events in and across a three-week design project during which student designers worked with community partners to develop a solution for differently-abled children. The video and transcript data we possessed was collected and organized by members of the DTRS-2014 program. Table 1 provides an overview of the video data, which included eight videos recorded during July 2013. The individuals within the videos included (a) nine students from Purdue University participating in a service-learning course, (b) two instructors, Cate who was a "senior" instructor and Ellie who was a "student" instructor, (c) numerous project partners who varied from video to video, and (d) an audience of assorted faculty, staff, and students in the final design presentation video. The videos ranged from roughly ten minutes to one hour in length. The videos were recorded using a single camera, with the exception of video six where two cameras were used and the video output displayed two separate angles side by side in one video. These videos represented debriefing, brainstorming, and feedback sessions through which the student designers communicated their designs, design activities, and experiences and received feedback from instructors, project partners, and peers.

Table 1.Data Overview

\begin{tabular}{llrl}
\hline$\#$ & Video Title & Length & People within the Video \\
\hline 1 & Partner Debrief \#1 & $40: 57$ & 4 project partners, all students and instructors \\
2 & Brainstorm Review & $59: 34$ & All students, 1 student instructor \\
3 & Partner Debrief \#2 & $30: 56$ & 1 project partner, 3 students, 1 senior instructor \\
4 & Advisor Debrief \#1 & $11: 22$ & 2 instructors \\
5 & Advisor Debrief \#2 & $11: 35$ & 6 students, 2 instructors \\
6 & Partner Review & $19: 03$ & 2 project partners, all students, 2 instructors \\
7 & Advisor Debrief \#3 & $8: 53$ & 2 instructors, all students \\
8 & Final Review & $40: 10$ & all students, 2 instructors, 14 assorted faculty, staff, and \\
& & & students \\
\hline
\end{tabular}

In most of the videos, the audio was clear but there were many instances of crosstalk or inaudible responses. The video quality was fair, and the angle of most videos often provided a one-angle perspective, essentially not including anyone who happened to be off-screen. For the purposes of this study, this was only a minor concern, as our goal was to explore the role of empathy by the designers for the end users who are not featured in the videos. These users are differently-abled child campers, many of whom use wheelchair. The fact that the campers are not featured in the 
videos does pose a limitation for this study, as we do not see the frequent interactions between campers and the student designers over the three-week period in which the data was collected. Nonetheless, in the process of designing, students verbally reflected on their experiences with the campers during many of the videos. It is these verbalizations, and in a few instances physical actions, on which we rely for our analysis. We recognize even this may be missing internal, nonverbalized thoughts or feelings of empathy by designers towards users, as well any feelings of empathy experienced or communicated during design activities that were not recorded.

\subsection{Critical Events}

The critical events selected represent any instance where designers employed user-centric knowledge towards the development of a design solution. Alone, this does not necessarily indicate that empathy was present, but rather that empathy may have played a role in generating a design response. After reviewing the data separately, the two authors compiled all instances they believed fit this categorization. More than 100 instances over the 8 videos were found and analyzed. The largest amount of these instances were from the second video, where the students brainstormed possible design alternatives within their groups. The second most prevalent sources were videos six and eight, where the students presented their proposed design solutions to project partners and community reviewers. Part of the reason for this is the nature of our exploration: we wanted to uncover empathy by the designer for the user. In videos two, six, and eight the designers did the bulk of the talking, whereas in all other videos much of the discourse was by the instructors or project partners. One exception to this is video seven. Here the designers did much of the talking, but they referenced their experiences with the users with minimal explicit reference to proposed design solutions.

\subsection{Developing Codes or Themes}

Once we identified critical events, we inductively coded these segments of data using the theoretical framework and the identified existing conceptualizations of empathy as a loose guide. This emergent coding process allowed us to explore what empathy looks like within design without being constrained to a nuanced differentiation in types of empathy from other fields, where the focus tends to be on direct one-to-one relationships. As is likely the case within engineering, we anticipated the means by which empathy manifests within a design project may be slightly different from general conceptions of empathy that hail from fields such as nursing, counseling, and neuroscience (Strobel et al., 2013). The development of codes was iterative with many discussions between the two authors taking place throughout the coding process before coming to an agreed upon final coding scheme.

\section{Results}

The service-learning videos provided a unique data set for exploring how empathy operates within the space of human-centered design and how designers generated concepts relative to their understanding of the user. Thematic analysis of over 100 critical events revealed seventeen underlying patterns of how designers employed user-centric knowledge during the design process. Five of these patterns demonstrated a focus on user-centric knowledge but little to no empathy, and are therefore not explored in-depth in this study. 
The remaining twelve patterns mapped onto four themes which represented how empathy was used towards the development of design solutions. The developing understanding theme refers to design behaviors oriented towards identifying and comprehending the perspectives of potential users. The identifying criteria and constraints theme refers to utilizing the designers' empathic understanding of the user in order to set design goals and parameters. The generating design concepts theme refers to how the designers' empathic understanding of the user led to the generation of new design concepts. The evaluating design concepts refers to how designers used empathy to determine the appropriateness of design concepts for the users. Table 2 presents each of the seventeen original patterns and how they fit into the four themes. Patterns in gray font indicate those that were user-centric but were only minimally empathetic, if at all.

Table 2.Themes Patterns of User-Centric Design Behaviors in Relation to Design Outcomes

\begin{tabular}{|l|l|l|l|}
\hline $\begin{array}{c}\text { Developing } \\
\text { Understanding }\end{array}$ & $\begin{array}{c}\text { Identifying Criteria } \\
\text { and Constraints }\end{array}$ & $\begin{array}{c}\text { Generating Design } \\
\text { Concepts }\end{array}$ & $\begin{array}{l}\text { Evaluating Design } \\
\text { Concepts }\end{array}$ \\
\hline $\begin{array}{l}\text { Direct observation of } \\
\text { Users }\end{array}$ & Empathic concern & $\begin{array}{l}\text { Refine user } \\
\text { suggestions }\end{array}$ & Check with user \\
\hline $\begin{array}{l}\text { Mediating } \\
\text { Stakeholder }\end{array}$ & $\begin{array}{l}\text { Synthesize empathic } \\
\text { knowledge }\end{array}$ & $\begin{array}{l}\text { Design for user- } \\
\text { centered criteria }\end{array}$ & Imagined use \\
\hline Projection & & Integration & \\
\hline Simulation & & -Assumed needs & \\
\hline Immersion & & -Prior experience & \\
\hline -User as self & & -Self as user & \\
\hline & & -Direct suggestion & \\
\hline
\end{tabular}

Figure 1 shows a process map of the designers' empathic design process which emerged from our mapping of these themes and their underlying patterns. The light green bubbles on the upper portion of the figure represent the stakeholders involved. The light blue boxes represent the distinct design outcomes, or the themes shown in Table 1. The bolded text that links any two bubbles represents one of the seventeen emergent themes listed in Table 1. The patterns listed in black text demonstrate the uncovered patterns which show empathy by the designers towards the user. Further, these patterns show the connection between a stakeholder and a design outcome, or how one design outcome may lead to another. The user-centric but not necessarily empathic patterns are shown in light gray text to demonstrate alternative ways user-centric knowledge contributed to the design process. 


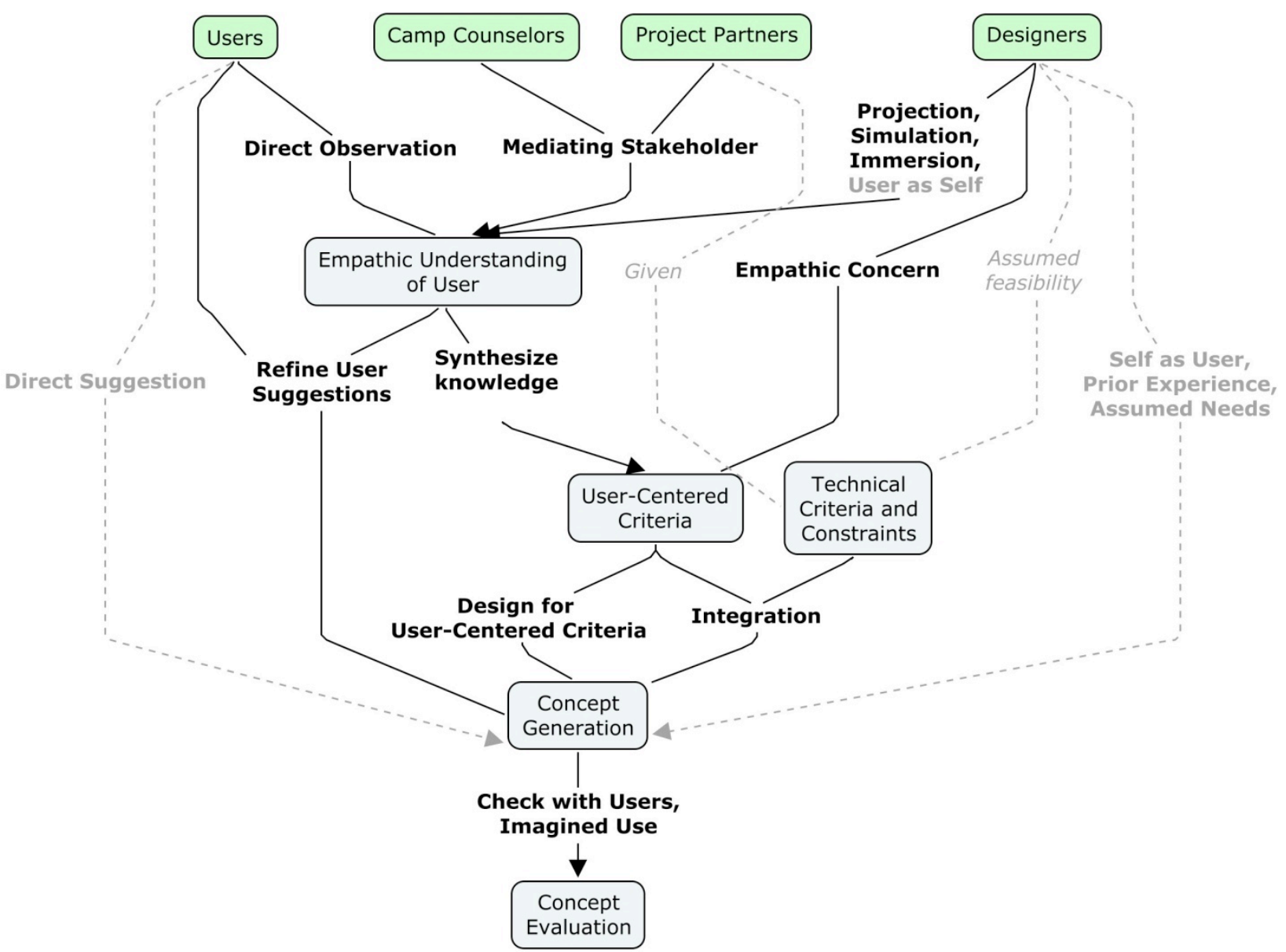

Figure 1. Process Map for Designers' User-Centric Concept Generation Pathways

Implicit in Figure 1 is that any process stemming from a stakeholder other than the designer involved the designer either performing the action or processing information relative to the stakeholder from which the pattern stems. This graphic shows there were a variety of pathways the designers used throughout their process, and the variety of outcomes generated from their empathic design processes. For example, sometimes the outcome was intrapersonal (e.g. an empathic understanding of the user) while other times it lead directly to a design outcome (e.g. user-centered criteria) and in two patterns played an evaluative role (e.g. check with users).

In the following sections we explain each of these empathic patterns in detail. The sub-section headings depict the outcome-oriented themes and the sub-headings represent the emergent patterns, or the processes that led to these outcomes. We start with the one intrapersonal outcome, portraying how designers developed an empathic understanding of the user, and end with three distinct categories of design outcomes: (a) identification of design criteria, (b) generation of a design concept, and (c) evaluation of design concepts. 


\subsection{Developing Understanding}

Five patterns emerged from the service-learning videos corresponding to this initial theme. These patterns depicted how designers developed an empathic understanding of the users' wants and needs. Figure 1 shows which stakeholder each of these processes arise from directly. Interestingly, this pathway was generated from each of the stakeholders we identified: the campers themselves, the project partners, camp counselors, and even amongst themselves.

\section{Direct Observation of Users}

This first pattern portrays the idea that designers developed an understanding of users through direct observations of the users within a real-world context. Here the orientation of the designers' perspective was user-focused. The student designers within the course had several interactions with the users during the two weeks spent at Camp Riley. Throughout the design reviews the students made numerous explicit references to their observations. For example, Jia noted "Normally, we'll be, I, I consider to help them [the kids in wheelchairs] and they - if the ramp is going up, I saw the kid is holding the back part of the wheelchair just in case they fall down" [emphases added]. Sebastian followed this up with a reference to one of the campers, stating, "He was doing that. Like whenever he was going over big bumps he would just grab behind on the wheelchair to hold himself in place." These explicit statements articulate designers' observations of a user in-action, where the designer's understanding of the user's perspective is seemingly implicit in each depicted instance.

\section{Mediating Stakeholder}

This second pattern highlights how designers developed an empathic understanding of users by gathering input from mediating stakeholders. This other-oriented empathic understanding was primarily gathered through direct conversations with the project partners and camp counselors regarding what the campers would want or need from the design. This pattern was evident through statements such as Claire's:

One of the things that they [project partners Todd \& Dominic] expressed is that when the kids go down the zip line they [the kids/users] want to have their friends cheering them on and telling them, like go now and having them [their friends] watch.

\section{Projection}

This third pattern depicts the process by which designers developed an empathic understanding of the users by mentally projecting themselves into the world of a fictitious design. Here designers employed self-oriented perspective-taking to develop a generalized understanding of the users. For example, Jia stated, "If I use a wheelchair, I may get bored making the - I mean rolling around." Here, Jia is imagining the world through her own eyes as if she were to be using a wheelchair "rolling around" the tree house and she hypothesizes that this may result in boredom. In a similar manner, Ellie stated:

What I like about that spiral design is the thought of like maybe starting tight and the whole thing kinda gets wider as you go up, 'cause I'm thinking from a visual 
perspective, this is going to be a long ramp. If I'm down low, do I want to really be able to see the ramp structure above me? Is there something that we could do to the underside of the ramp to kinda hide it or like hang plants from it, or something? Make that interesting to look at, or hide it so it doesn't feel like you're on this really long ramp. [emphases added]

\section{Simulation}

This fourth pattern represents how designers imagined themselves in the user's situation and used that simulation to derive an understanding of the user within the user's own context. While this pattern contains self-centric elements similar to projection (i.e. the designer experiencing the user's world from his or her own perspective) the goal is other-centric (i.e. to perceive elements of the user experience). As such, this pattern is pluralistic, showing how the designer reasoned back and forth from self to other. In the only example of simulation in the design review sessions, Clark simulates the experience of a camper in a wheelchair. His goal is to understand how the camper may view nature over a hand-rail by sitting in a chair and using his hands to simulate the railing.

When I think of going in the trees, I wanna be able to see like from the ground up, the whole view. And when we went to the lake yesterday and we were sitting at kinda like the outlook part of the railings I feel like if someone's sitting [Clark sits down in a chair and holds his hands up in front of his head to show is visual vantage point] in a wheelchair, they may not get the whole experience from the ground up. So maybe having like parts along that are clear so they could actually feel like they could view everything.

\section{Immersion}

This fifth pattern represents the process by which designers immersed themselves in the lives of the users to develop a holistic understanding of the users' wants and needs. This immersion included numerous activities, such as participating in the same activities as the campers, dining with the users, and through informal and formal conversations. We depicted this act of immersion as other-oriented, as the designers gathered a variety of information about and from the campers in order to develop empathic understanding of the campers, and this process tended to lack self-orientation except in the way the designer experienced the context as him- or herself. It is unclear exactly how well designers were able to understanding user perspectives through immersion, but there was a clear attempt to experience the context as a user. As an example, Jia explained, "When I played a game with them, the wheelchair soccer game, I kind of understand that... I have a chance to see what they experience and how they feel." Naomi described the interview aspect of immersion, along with how the immersion influenced the design team's generalized empathic understanding of the users and, in turn, their generation of design concepts:

And on Tuesday, we got to interview the campers. So we interviewed ten different campers and we gave them, [showing some paper slips] um - this is just one of the examples. So we would ask them, like what kind of things do you like to do, would you like to be able to in treehouse and then we would like lay out all these different pictures and kind of have like, you know, a point to pick, oh, this would be cool or this would be cool. And then as we they were going through 
these sort of questions, we also had them individually come up with their own ideas, so they were drawing or writing.

\subsection{Identifying Criteria and Constraints}

Two patterns underlay this second theme. These patterns depicted either how the designers' empathic understanding of the users' or their concern for the users generated design criteria or constraints.

\section{Empathic Concern}

This pattern depicts how designers placed an emphasis on target areas, namely safety and comfort, as a probable result of having empathic concern for the user. These target areas were not directly described by users or mediating stakeholders, but instead focused on the well-being of the users. These target areas represented generally applicable target areas (i.e., safety and comfort would be important for any potential user), but manifested in ways that are directly appropriate for the specific users the designers were focusing on. As these target areas are not directly requested of the designers, but are well thought out in the context, they likely stem from empathic concern for the user. For example, Ellie stated:

In terms, of, um, safety, I'm just thinking about this ramp, it sounds like it's gonna need to be over a 100 yards. It's gonna be really long. So we have this really long entryway. In terms of safety, is there a concern if the child would need to be evacuated from the tree house quickly - there needed to be quick route out that's not that really long ramp?

It is interesting to note that the student designers demonstrated concern beyond what was requested or required by the project partners. Robert's quote below, for example, lends support to the notion that constraints were generated by the designers' empathic concern for the wellbeing of the campers:

That's something we talked with the directors a lot about. Um, we really wanted to include some sort of emergency exit. They did not seem very concerned about that. Um, which was a little surprising but they thought the ramp should be sufficient and they have a lot of procedures, safety procedures in place to make sure that the kids who are going up will be, you know, with counselors and with people who are able to take care of them.

\section{Synthesize Empathic Knowledge}

This pattern portrays how designers used their empathic understanding of the user to synthesize further design constraints and criteria. In the student designers' language, they developed "components", or categories that design concepts fell into. The students distinguished these components along two criteria: experiential and technical. The students then further developed and refined these components by building on and synthesizing their empathic understanding of the user. For example, Naomi stated: 
And so we did, from all of that, is we saw, okay, what are some of the common themes that the kids want, what are some of the - you know, like a lot of them are like, you know, a day spa, relaxing, you know, a yoga room. Well, the theme kind of is they wanted to relax and they want - so we really tried to look for what's the motivation behind the ideas that these campers are coming up with.

\subsection{Generating Design Concepts}

This pattern had three underlying patterns, with each stemming from a distinct outcomes of the empathic design model depicted in Figure 1. The first pattern stemmed from the designer's empathic understanding of the user, whereas the second stemmed from user-centered criteria, and the third involved an integration of user-centered criteria and technical constraints.

\section{Refine User Suggestion}

This pattern depicts the process by which designers developed a design concept by refining usersuggested design concepts by juxtaposing these suggestions against the designer's empathic understanding of the users. The goal of this refinement was to mold the suggestion to better suit the needs of the user who suggested the concept. In some cases, such as Clark describing ramp design, this process involved modifying one user's suggestion to make the design more broadly applicable to other users in the context:

One of the camper's idea that we actually didn't think of and love was to have a clear surface that they could go over on the ramp. And most of the campers loved this idea but a couple were kind of hesitant, you know, maybe they had a fear of heights. So one idea that we all kind of came up with was have a challenge by choice. So maybe you could have one part of the ramp that kind of branches off that has, you know, this clear material and they could see down to the ground.

In other instances, such as Sebastian describing the modified wind chimes and musical boards, the designers incorporated elements of users' underlying wants and needs to improve the users' suggestions.

So some of the ideas that the campers came up with were, uh, wind chimes... and also playing with instruments. Being able to play with music was big for them. Uh, so some of the concepts that we came up with... Um, and then wind chimes made of recycled materials, and uh, some glow-in-the-dark elements. And then musical boards, this was a great one that someone came up with, where someone on a wheelchair could actually roll over the floor and it would make a song, like from musical piano or something like that.

\section{Design for User-Centered Criteria}

This pattern represents the designers' intentions to develop design concepts that meet the usercentered criteria, which was developed by designers through their empathic understanding of the user (e.g. immersion and direct observation). For example, designers synthesize knowledge to generate experiential target components, which in turn the designers used to develop design 
concepts such as relaxation, fun, and sensory. Clark described the development of the cheering platform based on the nature component:

So after talking with you guys [project partners] and the campers, it seemed one of the main objectives was to get the kiddos off the ground and into the trees and connect more with nature. So just one example here is, um, this is actually illustrating a cheering platform, so they could go into the ramp and then cheer on their fellow campers as they get on the zip line.

Clark later described that some design concepts targeted and met multiple components the designers had identified, and suggested the design could be modified based on the components that were to be emphasized:

So one thing we noticed was a lot of these design ideas don't fit into one particular category, they, they all involved different aspects. So one example of this could be like a sensory board or a sensory wall. You know, it could be part of the structure, it could be an entire wall but inside of the treehouse, maybe it could be like a moss wall or be living and have growing elements. Uh, it's sensory, you know, our campers would come up and touch and feel all the different elements. Um, it's fun, and it's just one of the many examples that incorporates the wide range of all the ideas.

\section{Integration}

This pattern depicts how designers integrated experiential components into the technical design. As in the previous pattern, designers targeted specific experiential components determined through empathic understanding of the stakeholders. However, instead of developing designs to solely meet those criteria, they integrated these components into existing designs that were based on purely technical criteria and constraints (e.g. the need for railings on the ramp and choice of building materials). Incorporating user-oriented experiential components to the required technical design elements was not necessary. The finding that designers attempted this integration demonstrates affective components of empathy, along with the cognitive empathy necessary to make the integration successful. In this quote, Sebastian described a way to incorporate the experiential component of sensory by the utilization of cut-down trees for the structure.

We're gonna be cutting down a lot of trees for this, so my idea was to take those trees and recycle them as railing, um, on the ramps. So that way - and just completely unprocessed, so that way they would actually when they're going up, they would be able to touch the trees as they're going up the ramps.

\subsection{Evaluating Design Concepts}

This last theme had two underlying patterns, each of which stemmed directly from the designers' empathically generated design concepts. This evaluation portrayed the designer's goal of seeking 
empathic accuracy (e.g. that the solutions they proposed actually aligned with the user's wants and needs)

\section{Check with Users}

This pattern provides an overview of how designers checked the suitability of their design by gathering more information about the user or by directly presenting the concept to users. The process is depicted as other-oriented, as the designer seeks to justify or modify a pre-generated design concept through the perspective of the users themselves. For example, Richard explains the users' reactions to a presented design concept:

So just one of many ideas we came up with was having a wall in the treehouse on which the campers could, you know, get some paint on their hands and leave their handprint on the treehouse. We thought that'd be a really fun activity and a good way to, you know, interact with the treehouse and make friends. And a lot of the camp counselors and campers loved that idea because it' $d$ be a nice way to leave their mark on the treehouse.

\section{Imagined Use}

This pattern represents the process by which designers imagined what the user would do naturally (as opposed to what the user would like to do) if a generated design concept were implemented. In this process, designers are essentially evaluating a design concept based on their own understanding. As such, their perspective throughout this evaluation is self-oriented, but the accuracy of the designer's evaluation is contingent upon their own affective and cognitive alignment with that user. For example, Jordan suggested, "I didn't know if it should be like square if the corners are easier for them to like push off. Someone told us that they grab that and then like they can turn easier." When stating this, Jordan reached behind her, projecting herself into the user's real-world context of the fictitious design, and used this projection to evaluate the newly generated design concept.

\section{Discussion}

In this study, we explored the role of empathy in design through analysis of videos of interactions between student designers, project partners, and course instructors. Our aim was twofold: (a) to understand how designers develop an empathic understanding of differently-abled users within a service-learning course and (b) to explore how designers utilize their understanding of users to identify, modify, and select design concepts for a large-scale tree house. We inductively generated four themes representing how empathy was utilized by the student designers. The first of these, developing empathic understanding of the users, is distinguishable as an intrapersonal outcome as opposed to a design outcome. However, this theme was a pathway to one of the remaining three themes: (i) identification of criteria and constraints, (ii) generation of design concepts, and (iii) evaluation of design concepts. Each of these themes contained several underlying patterns, and taken together, the relationship between these patterns and themes mapped a structure showing how these student designers progressed through an empathic design process. 


\subsection{Designers Employed a Coherent Empathic Design Process}

The student designers in this study employed empathic techniques throughout multiple phases of their design process in a series of distinct patterns with distinct outcomes. The content and pervasiveness of these patterns of design behavior suggests a comprehensive empathic design process employed by the student designers. This process is demonstrated by our model shown in Figure 1, and this empathic design model allows us to make a series of assertions. First, there was evidence of students developing an empathic understanding of the users through immersion in the user context, simulating user behaviors, projecting themselves into the users' situations, direct observation of the users, and discussions about the users with other stakeholders who had intimate knowledge of the users. Second, the designers used empathic concern alongside this empathic understanding to synthesize their user-centric knowledge into user-centered design criteria. Third, students developed and refined design concepts by utilizing their empathic understanding of the users and by gathering direct suggestions from the users. Finally, students evaluated their generated design concepts by imagining users employing the design concepts in the real-world and by checking their design concepts directly with the users.

While this process is limited in that it was generated from one data set and therefore in one context, it has a strength in that the context was real-world, where designers had the opportunity to directly interact with the users for whom they were designing. In theory, this model should be translatable to other contexts, but future work will be needed to validate and refine the empathic design process uncovered herein.

\subsection{User-Centric but Non-Empathic Behaviors Play a Key Role in Empathic Design}

While empathic processes enabled the designers to navigate through the design process to concept generation and evaluation, non-empathic elements also played a key role in the students' design process. To highlight this, the gray areas in Figure 1 include non-empathic modes of developing user-centric knowledge. Our findings indicated patterns along these user-centric but non-empathic modes which included (a) assuming user needs, (b) using prior self-knowledge and transposing that onto the user, (c) considering what the designer would want were he or she in the user's place, and (d) considering the designers' own perspectives in the users' context to generate an other-oriented empathic understanding of the user. It is unclear based on our analysis the extent to which these behaviors may have interfered with or possibly supported the empathic elements of the designers' process. It is possible that more self-oriented behaviors can aid a designer's understanding or concern for the user, but it is also possible that over-reliance on nonempathic themes may decrease empathic accuracy and distract the designers from more empathic design behaviors. In relation to this assertion, in the following two sections we discuss how empathic accuracy may be attained, starting with a description of the designers' perspectiveorientation in the described patterns.

\subsection{Pluralistic Reasoning Allows the Designer to Enter the Users' World}

One emergent theme generated from our findings (which we removed to simplify the findings) involved the perspective-orientation of designers towards users. In several of the themes that were deemed non-empathetic, designers seemed to use a self-oriented perspective to drive the design forward, while in nearly all of the themes depicted as empathy, designers relied primarily on an other-oriented, user-specific perspective. A key distinction between these self-centric and 
other-centric patterns observed are that while both represent an attempt to provide appropriate and nuanced design for the particular context, only other-centric design actions (and only some other-centric actions at that) directly tied the design concepts to needs or wants directly communicated (verbally or non-verbally) by users. However, in many of the instances described, there was a duality of perspective-taking, where the designer would reason back and forth between this self-other dichotomy. Some of these "pluralistic" instances demonstrated how selfcentricity can be used to gain a better understanding of users, and this explains the "key" role of the user-centric but non-empathic behaviors in empathic design. By imagining themselves as users or in the users' shoes, designers may be able to form a better connection with the users, and thus move outside their typical worldview to understand what the user might prefer while also relying on their expertise as a designer. This technique, when used well, may actually lead to designs that move beyond what a designer or user alone could have imagined through the integration of both designer expertise and situated, contextual knowledge of the user's needs.

\subsection{Designers Seeking Empathic Accuracy of Users}

Even when reasoning back and forth between a self-other perspective, it is difficult to accurately understand others' perceptions, beliefs, or values. Accurate empathic understanding is filtered through the empathic individual's unique lens (Oxley, 2011), the matching of the observers' state of mind with the observed (Decety \& Jackson, 2004; Levenson \& Ruef, 1992), and antecedent knowledge and abilities (Davis, 1996; Davis \& Kraus, 1997). Thus, our analysis has articulated how designers strive for empathic accuracy, but it is unclear exactly how appropriate their othercentric design solutions were for the users. For example, designs relying on understanding developed through mediating stakeholders may only be appropriate if those mediating stakeholders accurately understood the users in the first place, and assuming they effectively communicated this understanding to the designers. Nonetheless, designers demonstrated empathy and strove for appropriateness when checking design concepts developed through selfcentricity with the potential users, and modifying based on the user's feedback. The designers kept open a two-way communication stream with the users, where they gathered input from the users, synthesized or refined their ideas, and then gathered more feedback. This process of continual two-way feedback, assuming there was a relationship of trust and the users felt comfortable and were able to share their thoughts, is perhaps the only mechanism to ensure our understanding of others is accurate.

\subsection{The Role of Immersion in Design Thinking}

Immersion in the lives of individuals different from oneself, assuming this other is receptive and open to such an act, may be necessary if anyone, designer or not, is to fully comprehend the needs of another (McAllister \& Irvine, 2002). Zoltowski et al. (2012) suggested "immersive experiences involving real clients and users were important in allowing the students to experience human-centered design in more comprehensive ways," and found that the majority of students who experienced "empathic design" had immersive experiences with the users of their designs (p. 49). On one hand, immersion does not imply empathy, but it does seem to be one of the primary mechanisms of gathering needed antecedent knowledge for accurate empathy (Davis, 1996; Oxley, 2011). Although not captured within the thematic analysis presented here, it is evident that most, if not all, of the student designers appearing in the videos had immersive experiences with the children from Camp Riley. One video in particular, video 7, was filled with 
references to such immersive experiences. Although the discourse in this video was mostly lacking explicit reference to the proposed designs, it showed that the information gathered through immersion undoubtedly influenced the designers' empathy for the users. Looking across all critical instances, immersion into the users' context through participation in their activities, observation, and conversations clearly influenced the design process. Through these interactions, the student designers identified specific design concepts the users would want as well as the meaning of those potential designs to the users. Designers then employed this understanding to develop activities and design concepts that would meet these now understood needs and wants.

We believe immersion serves an important function in design when designing for any stakeholder, as inevitably stakeholders may have unique needs of which the designer is unaware without such immersion. Oftentimes information is gathered indirectly or through one-shot collection periods rather than through extended interaction with the source. Within all fields of qualitative research, when we read the work of another scholar, we decide whether to trust if their statements accurately represent the thought patterns or experiences of their study population (e.g. you may agree or disagree with the themes presented herein). Studies are validated through repeatability testing and seeing if similar results are generated in novel contexts. Similarly, the designers could have relied solely upon information gathered through their project partners in this study, but doing so would run this risk of either inaccurate or incomplete understanding of the users' needs and desires. For example, any discourse on the role of bubbles within the treehouse design (which the designers made numerous references to in their brainstorming session) would most likely have been omitted - as it has been up to this point in this study.

\subsection{Imagined Constraints Limit the Matching Between Users' Needs and Design Ideation}

External factors, outside of the needs and perceptions of users, influenced the design. These included criteria and constraints set by the clients, the wants and needs of camp staff (translating what they think campers need), and technical limitations. These challenges were, perhaps, not as significant as the limitations posed by the self-centric patterns as (a) many of the criteria and constraints were set based on user needs perceived by camp staff and directors, who had known and interacted with the users for a longer time, and perhaps in greater depth, than the designers, and (b) students made a conscious effort to integrate user-centric elements into their design to meet technical requirements. Sebastian's quote from the integration sub-section is particularly telling of this effort. Still, the empathic understanding of users gathered through mediators may not be equal to the awareness students would build through immersion, and rigid technical requirements set by these mediating stakeholders could potentially limit the designer's capacity to apply their empathic understanding to the design.

\subsection{An Empathic Environment Induces Empathy for Users}

In traditional design projects, empathy may be less evident or abundant than it was within the videos analyzed herein. Perhaps the nature of the project (design for a specific group of users) or the design process carried out (EPICS Human-centered design process) allowed empathy to thrive. Perhaps it was the immersion of designers with users. While all of these are valid proposals, we also believe the environment itself within which the design was carried allowed empathy to flourish, as all stakeholders seemed to be empathetic with one another, and highly empathetic towards the user-group. The instructors were clearly empathizing with the users, with 
comments abounding such as, "I was really missing them that day we didn't see them at all." The majority of project partners emphasized the needs of the campers in their discussions with the designers, expressing a desire to deliver a unique experience to the campers based off their understanding of the users' experiences from years past. If empathy does have emotionally contagious implications (Barsade, 2002; Stiff, Dillard, Somera, Kim, \& Sleight, 1988) then it seems highly plausible that an environment with an abundance of empathy would propagate to the designers studied herein.

\subsection{Types of Empathy We May Have Expected to Find but Did Not}

In general, we did not derive an abundance of solely affective modes of empathy within the analyzed discourse. Automatic modes of empathy, where individuals match the internal state of another (de Waal, 2009), were beyond the scope of this work. While at times it seemed plausible that designers were exhibiting empathic concern, showing other-oriented emotive framing of ideas throughout the design process (Davis, 1996), affective instances such as this were not pervasive. Empathic distress, where an observer "feels distressed on observing someone in actual distress" which in turn leads them respond to the other to alleviate that distress (Hoffman, 2000, p. 4), was not found whatsoever. Of course, we did not see the interactions between campers and the designers, where presence of this mode of empathy would be more likely to be visible.

Although we can only speculate, despite not seeing certain patterns of empathy emerge from the data we analyzed, it is highly possible the designers exhibited some or all of these automatic or affective empathic tendencies outside of the coded video segments or even within the coded segments without making their mental processes explicit. For example, when all the students watched Clark sit in a chair as if he was riding in a wheelchair, it is possible each designers' mirror neurons fired (Decety \& Ickes, 2009) as they imagined themselves too riding in a wheelchair up the steep slope of their fictitious design. It is even plausible empathic concern permeated all of the design process for some of the designers.

\subsection{Limitations: What's Implicit isn't Explicit}

In performing this data analysis, the primary challenge was capturing internally held beliefs and preferences of the designers. Without a method of making the implicit thoughts of the designers explicit, we were limited in our capacity to understand all the ways the designers may have empathized with the users throughout the design process. As many of the non-empathic themes demonstrated, the student designers often suggested design concepts based on what they preferred, had previously experienced, or would experience if they situated themselves in the proposed design, as opposed to what the users would actually want or experience. There may have been elements of cognitive empathy present in these behaviors that were unobservable. It is also possible that empathic concern, an affective component of empathy, may be underlie many of the depicted partners, serving as an impetus for these design activities (although we reiterate there was minimal affective language throughout the analyzed videos). It is also possible that empathic concern is not necessarily a driving force throughout the design process, but rather it may serve as the motivation to begin the specific design project in the first place. Future work might focus on exploring empathic elements that are difficult to observe in team interactions and feedback sessions. 


\section{Symposium Connections and Broader Implications}

\subsection{Linking empathy to design thinking, acting, and being}

Traditionally, discussion of empathic design within the literature has focused on (a) what you, the designer, knows about the user, (b) how you come to know it, (c) why you come to know it, and (d) how that knowledge affects design outcomes (Leonard \& Rayport, 1997; Mattelmäki et al., 2014; Postma et al., 2012). While these explorations discuss what empathic design looks like, they lack explicit focus on the core construct, empathy, and how it functions throughout the whole design process. For example, what is the distinction between understanding the user and empathically understanding the user, and what implications does this distinction have for design practice?

This work provides some clarity to this issue by identify ways that student designers developed and utilized empathic understanding of target users. As depicted in Figure 1, this study presents a model of an empathic design process used by student designers who participated in a service learning course. This process demonstrates 12 empathic design behaviors, as well as 5 usercentered design behaviors that were not ostensibly empathic. This model also describes how empathy was utilized throughout the design process, and provides some indication of contextual elements that may either promote or inhibit empathy in the design process. This model, and its constituent elements, may provide fodder for future research on design thinking in both student and professional contexts. For example, what effect do the various empathic behaviors have on design outcomes? How are empathic behaviors integrated into experienced designers' processes?

While our analysis focused mostly on verbalized indications of empathy for users, empathy often takes physical or physiological forms (Batson, 2009), which themselves are often related to or can also lead to cognitive forms of empathy. At this symposium, Tenenberg, Socha, and Rot (2014) explored the role of body orientation, or stances, and the surrounding environment in the design process. These authors proposed that designers fluidly navigate through inscriptional, third-person, first-person, and phenomenal stances throughout the design process, and that these stances change in "conversation" with others and the design itself. The third-person and firstperson stances represent a dichotomy of seeing the design from a generic external viewpoint and experiencing the design as the user. The phenomenal stance integrates these two viewpoints and represents the designer simultaneously seeing and experiencing the design (Tenenberg et al., 2014). We argue that all three of these stances indicate a potential for developing and utilizing empathy for the user, thus our study further elucidates the potentially prominent role of empathy in designerly ways of being. The phenomenal stance may represent a particularly powerful practice of empathic design as it suggests the designer becomes attuned multiple perspectives, and navigates throughout the design with this higher-order holistic perspective.

\subsection{Empathy and the design context}

This paper has highlighted different ways in which empathy for users is demonstrated by student designers, as well as how empathic understanding factored into these students' design solutions. This understanding can help instructors incorporate empathy into their design projects. For 
example, guided immersive experiences with real-world users may be a means to encourage the designers to use empathy in novel design contexts beyond the given course. Further, seeing how the student designers in this study incorporated empathy into their design work may provide inspiration and a roadmap for other design students who would like to be more empathic in the design process, or instructors striving to incorporate empathic design strategies into their curriculum. Other studies at this symposium focused on key elements of the learning context, and found the context to guide the processes employed by the designers.

Based off discussion throughout and after DTRS 10, we propose that the context of the design reviews could largely inhibit or promote empathic design. For example, Purzer, Fila, and Dick (2014) compared final design review sessions in mechanical engineering, industrial design, and choreography. These authors noted that the primary consideration in mechanical engineering was technical functionality and that role of the eventual user was marginalized. Conversely, the primary consideration in choreography was ostensibly how the users (the audience) perceived the design (the dance) and how it made them feel. Empathy thus was a necessity in the choreography context and only of minimum usefulness for success on the mechanical engineering project. Goldschmidt, Casakin, Avidan, and Ronen (2014) also looked comparatively at disciplines. Their results likewise found that the designer's foci in each of the separate disciplines were largely distinct. While in the Mechanical Engineering group the focus was primarily technical, in one of the Industrial Design groups the facilitator's focus was primarily on the user's emotions. The expectations for "end result" for each groups varied from a focus "entirely on performance" in the Mechanical Engineering context to one where final product was "expected to be exciting" in the Industrial Design case.

These considerations bring to light several prominent questions. What contextual factors are most critical for promoting empathic design? Must there be a real client who the designer may interact with, an imagined user, or does it matter if there is no clear client(s) whatsoever? How does the nature of the task assigned instigate the process? Are students expected to generate concepts for a known client or simply optimize a technical problem? What do the design rubrics evaluate? Are human-centered design steps given explicit value, or is the focus centered on whether a technical design will meet specified constraints?

As the facilitator often defines the context, the facilitator plays a key role in guiding the students' learning and doing, and therefore plays a particularly powerful role in defining the context. As an example, Howard and Gray (2014) discussed how the facilitator or teacher may directly influence the designer's higher-order thinking of the "user experience". What is learned is what the student sees the instructor give value to. In the case of the mechanical engineering teams, consideration of the users was minimal, but the choreography instructors continually brought the student designers' attention back to how the piece made them feel and how it would resonate with the audience (Purzer et al., 2014). What Lande and Oplinger (2014) proposed is that design be considered "more than problem-solving" requiring "ambidextrous mindsets" for the designer flow between distinct "designerly ways of knowing, doing, and acting with user empathy at its core" (p. 3f). In order to help students to master beyond-technical skills, Lande and Oplinger suggested facilitators should see themselves as more than sharers of knowledge, but also "love" coaches, allowing affect to drive their teaching practices. 
Further, it seems that as the complexity of the design task increases, so too will the context, and in turn the number of users who have a stake in the outcome of the design will increase. The orientation we have focused on was that of the designers towards one specific group of users the campers. However, the list of stakeholders influenced by this design is much more extensive. It certainly includes the project partners and camp counselors, but it also includes other campers at this location, regulative organizations, contractors, and even the wildlife and surrounding environment. In a much more complex engineering system, aerospace vehicle design, Coso (2014) noted one of her primary issues is getting students to identify all stakeholders impacted, let alone empathize with these stakeholders. We believe the empathic design model we have developed could still be a guide for empathizing with stakeholders in these complex situations, but identification of those users who have the most at stake and the application of this model in respect to those users would need to occur individually, on a user-by-user basis.

\section{References}

Barsade, S. G. (2002). The ripple effect: Emotional contagion and its influence on group behavior. Administrative Science Quarterly, 47(4), 644-675.

Batson, C. D. (2009). These things called empathy: Eight related but distinct phenomenon. In J. Decety \& W. Ickes (Eds.), The social neuroscience of empathy (pp. 16-28). Cambridge, MA: MIT Press.

Batson, C. D., Early, S., \& Salvarani, G. (1997). Perspective taking: Imagining how another feels versus imaging how you would feel. Personality and Social Psychology Bulletin, 23(7), $751-758$.

Braun, V., \& Clarke, V. (2006). Using thematic analysis in psychology. Qualitative Research in Psychology, 3(2), 77-101.

Coso, A. E. (2014). Preparing students to incorporate stakeholder requirements in aerospace vehicle design. $(\mathrm{PhD})$, Georgia Institute of Technology.

Davis, M. H. (1983). Measuring individual differences in empathy: Evidence for a multidimensional approach. Journal of personality and social psychology, 44(1), 113126.

Davis, M. H. (1996). Empathy: A social psychological approach. Boulder, CO: Westview Press.

Davis, M. H., \& Kraus, L. A. (1997). Personality and empathic accuracy. In W. Ickes (Ed.), Empathic accuracy (pp. 144-168). New York, NY: Guilford Press.

de Waal, F. (2009). The age of empathy: Nature's lessons for a kinder society. New York: Harmony Books.

Decety, J., \& Ickes, W. (Eds.). (2009). The social neuroscience of empathy. Cambridge, MA: MIT Press.

Decety, J., \& Jackson, P. L. (2004). The functional architecture of human empathy. Behavioral and Cognitive Neuroscience Reviews, 3(2), 71-100.

Goldschmidt, G., Casakin, H., Avidan, Y., \& Ronen, O. (2014). Three studio critiquing cultures: Fun follows function or function follows fun? Proceedings of DTRS 10 Symposium, West Lafayette, IN.

Hoffman, M. L. (2000). Empathy and moral development: Implications for caring and justice. Cambridge, UK: Cambridge University Press.

Howard, C. D., \& Gray, C. M. (2014). Higher order thinking in design reviews. Proceedings of DTRS 10 Symposium, West Lafayette, IN. 
Iacoboni, M. (2009). Mirroring people: The science of empathy and how we connect with others. New York: Picador.

Lande, M., \& Oplinger, J. (2014). Disciplinary discourse in design reviews: Industrial design and mechanical engineering courses. Proceedings of DTRS 10 Symposium, West Lafayette, IN.

Leonard, D., \& Rayport, J. F. (1997). Spark innovation through empathic design. Harvard Business Review, 75, 102-115.

Levenson, R. W., \& Ruef, A. M. (1992). Empathy: A physiological substrate. Journal of Personality and Social Psychology, 63(2), 234-246.

Mattelmäki, T., Vaajakallio, K., \& Koskinen, I. (2014). What Happened to Empathic Design? Design Issues, 30(1), 67-77.

McAllister, G., \& Irvine, J. J. (2002). The Role of Empathy in Teaching Culturally Diverse Students A Qualitative Study of Teachers' Beliefs. Journal of Teacher Education, 53(5), 433-443.

Oxley, J. C. (2011). The moral dimensions of empathy: Limits and applications in ethical theory and practice. New York, NY: Palgrave Macmillan.

Postma, C. E., Zwartkruis-Pelgrim, E., Daemen, E., \& Du, J. (2012). Challenges of doing empathic design: Experiences from industry. International Journal of Design, 6(1).

Powell, A. B., Francisco, J. M., \& Maher, C. A. (2003). An analytical model for studying the development of learners' mathematical ideas and reasoning using videotape data. The Journal of Mathematical Behavior, 22(4), 405-435.

Purzer, S. e., Fila, N. D., \& Dick, E. C. (2014). A cross-case analysis of disciplinary identities communicated through design reviews. Proceedings of DTRS 10 Symposium, West Lafayette, IN.

Stiff, J. B., Dillard, J. P., Somera, L., Kim, H., \& Sleight, C. (1988). Empathy, communication, and prosocial behavior. Communications Monographs, 55(2), 198-213.

Strobel, J., Hess, J. L., Pan, R. C., \& Wachter Morris, C. A. (2013). Empathy and care within engineering: Qualitative perspectives from engineering faculty and practicing engineers. Engineering Studies, 5(3), 137-159.

Tenenberg, J., Socha, D., \& Rot, W.-M. (2014). Designerly ways of being. Proceedings of DTRS 10 Symposium, West Lafayette, IN.

Zoltowski, C. B., Oakes, W. C., \& Cardella, M. E. (2012). Students' ways of experiencing Human-Centered Design. Journal of Engineering Education, 101(1), 28-59. 


\section{Biographies}

Nicholas D. Fila is a Ph.D. student in the school of engineering education at Purdue University. He earned a B.S. in Electrical Engineering and a M.S. in Electrical and Computer Engineering from the University of Illinois at Urbana-Champaign. His research interests include empathy, innovation, and collaboration in engineering design.

Justin Hess is a Ph.D. candidate at Purdue University's School of Engineering Education, Masters student in Purdue's School of Civil Engineering and a National Science Foundation Graduate Research Fellow. He received his Bachelor's of Science in Civil Engineering in 2011 with a minor in philosophy and hopes to receive his MSCE in 2015, both from Purdue University. His research focuses on understanding engineers' core values, dispositions, and worldviews. His dissertation focuses on conceptualizations, the importance of, and methods to teach empathy to engineering students. He is currently the Education Director for Engineers for a Sustainable World and an assistant editor for Engineering Studies. 